\title{
Distributed Speed Control for Multi-Three Phase Electrical Motors with Improved Power Sharing Capability
}

\author{
A. Galassini, A. Costabeber, C. Gerada \\ Power Electronic Machine Control Group (PEMC) \\ The University of Nottingham, UK
}

\author{
A. Tessarolo \\ Engineering and Architecture Department \\ The University of Trieste, IT
}

\begin{abstract}
This paper proposes a distributed speed control with improved power sharing capability for multi-three phase synchronous machines. This control technique allows the speed to be precisely regulated during power sharing transients among different drives. The proposed regulator is able to control the time constant of the current within the $d q 0$ reference frame to a step input variation. If compared to current set-point step variations, the proposed droop controller minimises device's stress, torque ripple, and thus mechanical vibrations. Furthermore, since distributed, it shows improved fault tolerance and reliability. The design procedure and the power sharing dynamic have been presented and analysed by means of Matlab/Simulink and validated in a $22 \mathrm{~kW}$ experimental rig, showing good agreement with the expected performances.
\end{abstract}

\section{INTRODUCTION}

Multi-three phase electrical motors are gaining popularity thanks to the growing interest in the electrification of transportation systems [1]. Due to their advantages if compared against standard three-phase systems [2], multi-three phase electrical motors and multi-drive applications are still widely investigated, i.e. aerospace [3], [4], mining machines [5], [6], ships [7], [8], and road vehicles [9]. One of their main benefit is redundancy, leading to increased fault tolerance and reliability. On the other hand, system design and control complexity increase both on machine and on power conversion side, thus requiring higher development efforts. Furthermore, in order to guarantee constant operating power in case of partial failure, both machine segments and converters must be over-rated decreasing specific power (i.e. power-to-weight ratio) and power density (i.e. power per unit of volume). Among all the possible applications, multi-three phase motors have been widely developed in Integrated Modular Motor Drive (IMMD) scenario [10], [11]. In-fact, thanks to their intrinsic redundancy, they allow more reliable motor drive systems to be developed. Looking at Fig.s 1, full redundancy can be achieved only by the distributed speed configuration in Fig. 1b. Clearly, in case of drive fault in Fig. 1a, the system would be compromised. On the other hand, in the centralised speed configuration where all the currents are fed back to the drive, all the sub-spaces can be controlled applying the Vector Space Decomposition (VSD) [12], and for this reason it allows better current control to be achieved [13].

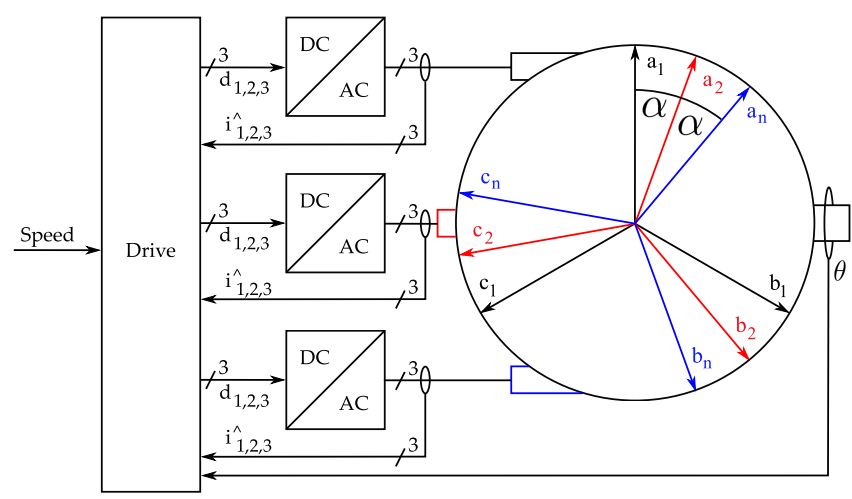

(a) Centralised speed controller. Not redundant on the drive side.

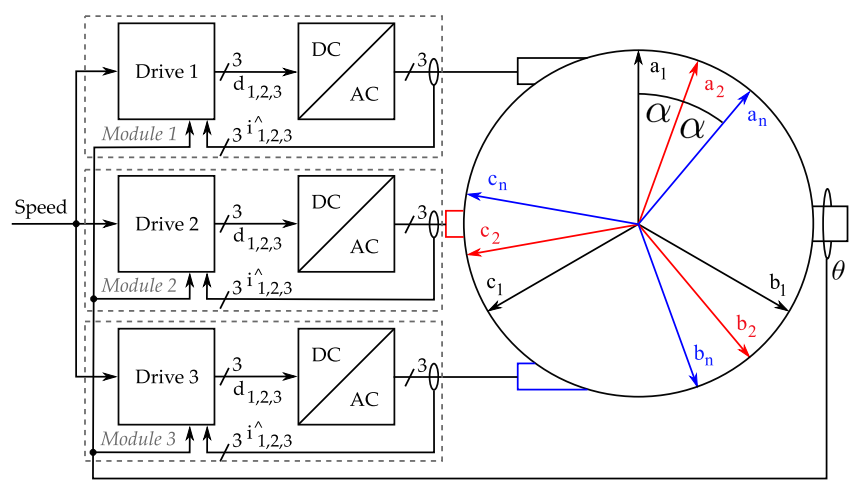

(b) Distributed speed controller. Redundant on the drive side.

Fig. 1. $d_{k}$ stands for duty cycle, $i_{k}$ for current $(k=1,2,3) . a_{j}, b_{j}, c_{j}$ are the phases of the j-th set of windings $(j=1 . . n) . \theta$ is the rotor position.

In this paper, a distributed speed control with power sharing capability - preliminarily introduced in [14], [15] - is extended and validated on a multi-three phase machine. Design and experimental validation of power sharing capability among three converters supplying a multi-three phase salient pole synchronous generator with one pole pair and nine phases is presented. Considering the split-phase winding arrangement in Fig. 1 with $n=3$ three-phase set of windings and defining $m=3$, the total number of phases is $N=n m$. Therefore, in Fig. $1, \alpha=\pi / N=\pi / 9$. In the next section, the current control loop design based on the first harmonic inductance is provided [12], [16], [17]. In Section III, the 


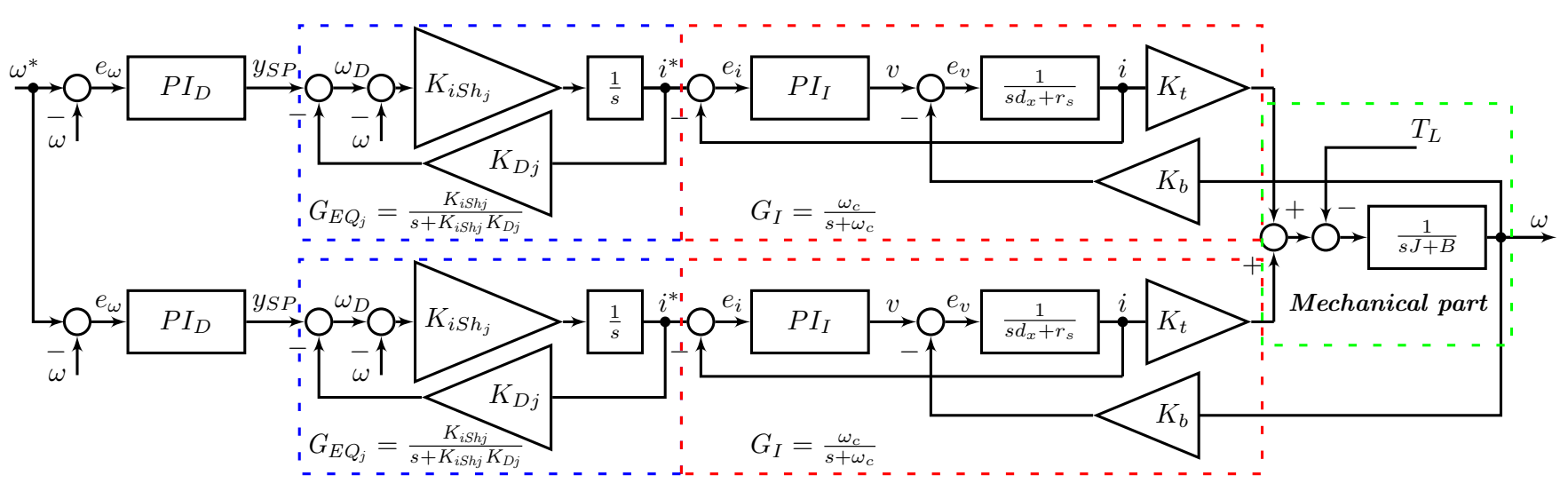

Fig. 2. $q$-axes of the proposed distributed speed control schematic within the synchronous reference frame without axes decoupling.

speeds control loop design is detailed and the Common Speed Reference (CSR) and Torque Follower (TF) configurations are explained [18]. Whilst Section IV introduces power sharing feature based on droop control strategy, Section V details the compensation loop needed to restore the steady state speed drop. In order to clarify the experimental validation shown in Section VII, Section VI summarises the whole control procedure. Conclusions are finally given in Section VIII.

\section{Current CONTRol}

The current control loops design has been based on the first harmonic inductance obtained from the Vector Space Decomposition (VSD) [12]. Considering switching delays $\left(T_{s w}\right)$ and current filter cut-off frequency $\left(\omega_{f c}\right), d-q$ current $P I$ controller proportional $\left(K_{p I}\right)$ and the integral $\left(K_{i I}\right)$ gains have been designed on the following plant:

$$
G_{I x}(s)=\frac{1}{s T_{s w}+1} \frac{1}{s d_{x}+r_{s}} \frac{\omega_{f c}^{2}}{s^{2}+\sqrt{2} \omega_{f c} s+\omega_{f c}^{2}}
$$

where $s$ is the Laplacian operator, $x$ is $d$ or $q$ axis, $r_{s}$ is the phase stator resistance, and $d_{x}$ is the first $d-q$ harmonic inductance calculated using the VSD [17].

\section{SPEED CONTROL}

Speed control is achieved either configuring all the drives in speed mode (Common Speed Reference - CSR) or configuring one drive in speed mode and the others in torque mode (Torque Follower - TF). The latter configuration is based on a master/slave approach, hence in case of master drive fault, the system is compromised. On the other hand, the CSR is distributed, guaranteeing system operation in case of fault of any of the drives. From now on, speed control will refer to the CSR configuration. Taking into account the current control loop cut-off frequency $\left(\omega_{c}\right)$, speed $P I$ controller proportional $\left(K_{p S}\right)$ and integral $\left(K_{i S}\right)$ gains have been computed on plant $G_{S}$ in (2), where $J$ is the inertia, $B$ is the friction, and $K_{t}$ is the machine constant relating torque and $i_{q}$ current.

$$
G_{S}(s)=\frac{\omega_{c}}{s+\omega_{c}} \frac{K_{t}}{s J+B}
$$

\section{POWER SHARING}

Power sharing in speed controlled multi-three phase motors can be achieved with tunable current set-points [18]. Current set-point step change would lead to discontinuity, hence current distortion and mechanical vibration. The proposed selfbalancing sharing controller guarantees smooth transients even with step variations in sharing ratios. The regulator has been derived by the so called droop control strategy - common in power transmission systems - where the basic droop characteristic is a linear function with a negative coefficient on the Frequency/Active-Power plane [19].

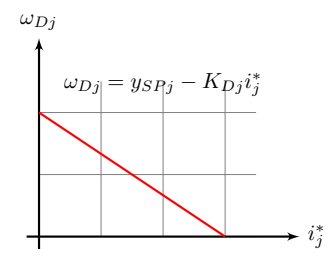

(a) Droop characteristic.

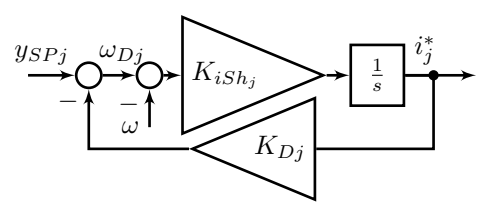

(b) Droop controller $\left(G_{E Q j}\right)$ implementation with speed feedback.
Fig. 3. $j$ denotes the $j$-th set of windings. $K_{i S h j}$ is the integral sharing gain.

$$
G_{E Q j}=\frac{K_{i S h j}}{s+K_{i S h j} K_{D j}}
$$

Translating the droop concept from power systems to multithree phase drives, the droop concept is a linear function with a negative coefficient $\left(K_{D j}\right)$ on the Speed/Current set-point plane (Fig. 3a). In Fig. 3b, the droop controller with the droop coefficient $K_{D j}$ is shown. $y_{S P j}$ and $\omega_{D j}$ are the speed and the internal (or drooped) speed set-point, respectively. The droop controller transfer function is in (3).

For simplicity, a distributed control schematic with just two sets of windings is shown in Fig 2. $T_{L}$ is the load torque, $K_{b}$ is the electro-magnetic force constant, and $P I_{I}$ is the current $P I$ controller. Due to the presence of the droop coefficient, the original speed set-point drop $\left(y_{S P j}-\omega_{D j}\right)$ must be restored with an outer loop, here referred as compensation loop. Final speed dynamics is achieved thanks to the $P I_{D}$ regulator. In the 
next sub-sections, design procedures for the droop regulator and the $P I_{D}$ controller for a given power sharing time constant and a given speed dynamics are detailed.

\section{A. Equivalent model}

Current $P I_{I}$ controllers are tuned on stator resistance and first harmonic inductance values in equation (1). Droop controller parameters design must be carried out considering the whole amount of power produced by all the converters. Assuming balanced condition where all the converters are producing the same torque - denoted with (ES) -, the control schematic in Fig. 2 can be simplified with the equivalent collective control scheme in Fig. 4 where paralleled cur-

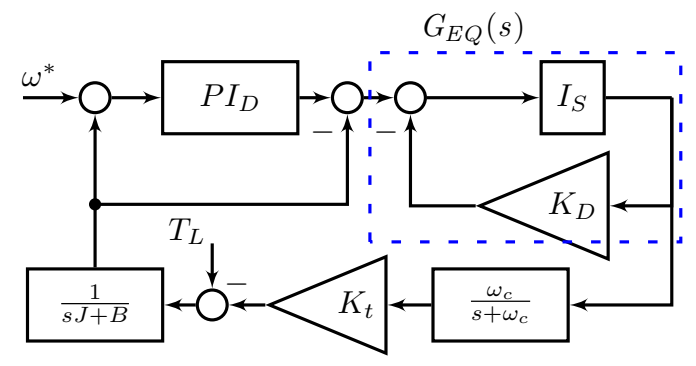

Fig. 4. Equivalent collective control scheme valid when the load power is equally split among the $n$ modules. $I_{s}=K_{i S} / s$.

rent loops (dashed red squares) have been replaced by the $G_{I}=\omega_{c} /\left(\left(s+\omega_{c}\right)\right)$ transfer function. The parallel of droop controllers have been replaced by the $G_{E Q}=n G_{E Q j}^{(E S)}$ transfer function valid if and only if [15]:

$$
K_{i S h}=K_{i S h_{j}}^{(E S)} n ; \quad K_{D}=\frac{K_{D_{j}}^{(E S)}}{n}
$$

The $K_{D}$ and $K_{i S h}$ parameters can be defined as the collective droop and collective integral gain coefficient respectively. Setting different values of $K_{D j}$ and $K_{i S h j}$, it is possible to set the amount of torque produced by each drive and the power sharing time constant during current transients. Once droop controllers are tuned, outer compensation loop can be designed on the final speed dynamics specifications.

\section{B. Current sharing dynamics}

The total power is given by the sum of all the nominal torques produced by each module multiplied by the shaft speed. Since currents and torques are directly proportional ( $\left.T=K_{t} i\right)$, the $j$-th power in $p . u$. is $P_{j}=I_{n o m, j} /\left(\sum_{j}^{n} I_{n o m, j}\right)$ where $I_{n o m, j}$ is the nominal current on the $q$-axis of the $j$ th module. From Fig. 2, it can be noticed that the current set-points are the output of the sharing regulators $G_{E Q j}$. Provided that in steady state the magnitude of the droop controllers in Eq. (3) is the reciprocal of the droop coefficient $\left(\left|G_{E Q j}\right|_{s \rightarrow 0}=1 / K_{D j}\right)$, the power produced by each module can be re-written like the following:

$$
P_{j}=\frac{1 / K_{D j}}{\sum_{j}^{n}\left(1 / K_{D j}\right)}=\frac{1 / K_{D j}}{\varepsilon}[p . u .]
$$

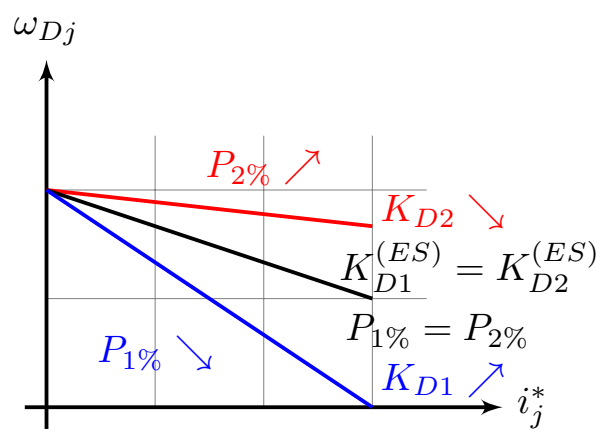

Fig. 5. Power sharing is achieved with different droop coefficients.

Thanks to Eq. 5, as long as $\varepsilon$ is kept constant, unbalanced power sharing can be achieved just changing the droop coefficients as shown in Fig. 5. However, constant speed of the shaft is guaranteed if and only if the collective sharing regulator transfer function is kept constant: $\sum_{j}^{n} G_{E Q j}=n G_{E Q j}^{(E S)}=$ $G_{E Q}$. Therefore, constant speed operation is achieved updating both the droop and the integral gain coefficient. Provided that $\sum_{j}^{n} P_{j}=1, G_{E Q}$ is kept constant by dividing the individual equal power droop coefficients $K_{D j}^{(E S)}$ by a factor $\xi_{j}=n P_{j}$ and multiplying the individual integral gain $K_{i S h j}^{(E S)}$ by the same factor $\xi_{j}$. Since the current sharing dynamics is governed by the droop controller $G_{E Q j}$, its closed loop time constant in Eq. (6) dominates the power sharing transient. Looking at Eq. (6), it is clear that constant sharing transient is obtained only updating both the coefficients.

$$
\tau_{\text {sharing }, j}=\frac{1}{K_{D j} K_{i S h j}}
$$

\section{COMPENSATION LOOP}

Aim of the compensation loop is to restore the speed drop introduced by the droop controllers and to guarantee adequate speed dynamics performance. Looking at the equivalent collective scheme in Fig. 4, the plant $G_{D}$ for designing the compensation $P I$ is described by Eq. (7).

$$
G_{D}(s)=\frac{\frac{K_{i S h}}{s+K_{i S h} K_{D}} \frac{\omega_{c}}{s+\omega_{c}} \frac{K_{t}}{s J+B}}{1+\frac{K_{i S h}}{s+K_{i S h} K_{D}} \frac{\omega_{c}}{s+\omega_{c}} \frac{K_{t}}{s J+B}}
$$

\section{CONTROL DESIGN APPROACH}

Based on the previous discussion, a possible design procedure for each module with power sharing capability is summarised here. The system has been designed considering a speed set-point $\omega^{*}=30 \mathrm{rad} / \mathrm{s}$. Referring to the equivalent collective scheme, $d$ and $q$ current controllers have been assigned the same bandwidth $B W_{C}=211 \mathrm{rad} / \mathrm{s}$ and the same phase margin $P M_{C}=65^{\circ}$ whereas the speed and compensation regulator has been designed with a $B W_{D}=6 \mathrm{rad} / \mathrm{s}$ and a $P M_{D}=60^{\circ}$. The droop loop, or sharing loop, has been set up with different bandwidth $\left(B W_{D}<B W_{S h}<B W_{C}\right)$ and phase margin $\left(P M_{S}\right)$ values in order to demonstrate 
TABLE I

DROOP CONTROLLER PARAMETERS

\begin{tabular}{|c|c|c|c|c||c|c|c|c|c|}
\hline \multicolumn{9}{|c||}{$\tau_{\text {sharing }}=0.001[s]$} & \multicolumn{5}{c|}{$\tau_{\text {sharing }}=0.030[s]$} \\
\hline$j$ & $P_{j}$ & Current & $K_{D j}$ & $K_{i S h j}$ & $j$ & $P_{j}$ & Current & $K_{D j}$ & $K_{i S h j}$ \\
\hline $1,2,3(E S)$ & $1 / 3(E S)$ & 2 & $1.5(E S)$ & $666.6(E S)$ & $1,2,3(E S)$ & $1 / 3(E S)$ & 2 & $1.5(E S)$ & $22.2(E S)$ \\
\hline 1 & $2 / 3$ & 4 & 0.75 & 1333.3 & 1 & $2 / 3$ & 4 & 0.75 & 44.4 \\
\hline 2 & $1 / 12$ & 0.5 & 6 & 166.6 & 2 & $1 / 12$ & 0.5 & 6 & 5.5 \\
\hline 3 & $1 / 4$ & 1.5 & 2 & 500 & 3 & $1 / 4$ & 1.5 & 2 & 16.6 \\
\hline
\end{tabular}

how the proposed strategy is able to control current sharing dynamics. Looking at the droop plane in Fig. 3a, the collective droop gain coefficient can be obtained imposing the maximum speed drop with the following Eq.: $K_{D}=$ $\Delta \omega_{\max } /\left(\sum_{j}^{n} I_{n o m, j}\right)$. The maximum speed drop would be the steady state output speed of the system without the $P I_{D}$ in nominal condition. In this particular case, the maximum delta has been set up equal to the $10 \%$ of the reference speed $\left(\Delta \omega_{\max }=3[\mathrm{rad} / \mathrm{s}]\right)$. Considering a total nominal current of $6[A]$, the collective droop coefficient $K_{D}^{(E S)}=$ $\Delta \omega_{\max } /\left(\sum_{j}^{n} I_{\text {nom }, j}\right)=0.5[(\mathrm{rad} / \mathrm{s}) / A]$ has been computed. Therefore, $K_{D j}^{(E S)}=n K_{D}^{(E S)}=1.5[(\mathrm{rad} / \mathrm{s}) / A]$. Looking at Table I, the integral gain $K_{i S h j}^{(E S)}=1 /\left(K_{D j}^{(E S)} \tau_{\text {sharing, } j}\right)$ has been computed for $1[\mathrm{~ms}]$ and $30[\mathrm{~ms}]$, respectively. Finally, dividing the droop gain and multiplying the integral gain by the same factor $\xi_{j}=n P_{j}$ (for $P_{j}=2 / 3,1 / 12,1 / 4$ ) power unbalancing has been obtained.

\section{EXPERIMENTAL VALIDATION}

The proposed droop controller has been validated on a multi-three phase salient pole synchronous generator with one pole pair and nine phases shown in Fig. 7. Machine parameters are as follows: $r_{s}=9.1 \Omega, d_{d}=0.045 H, d_{q}=0.114 H$, $K_{t}=3.06 \mathrm{Nm} / A, J=0.38 \mathrm{Nms}^{2}, B=0.14 \mathrm{Nms}$. The motor has been connected to three off-the-shelf two-level three-phase converters (IRMD22381Q demo board combined to the FP25R12KE3 power modules from Infineon) controlled

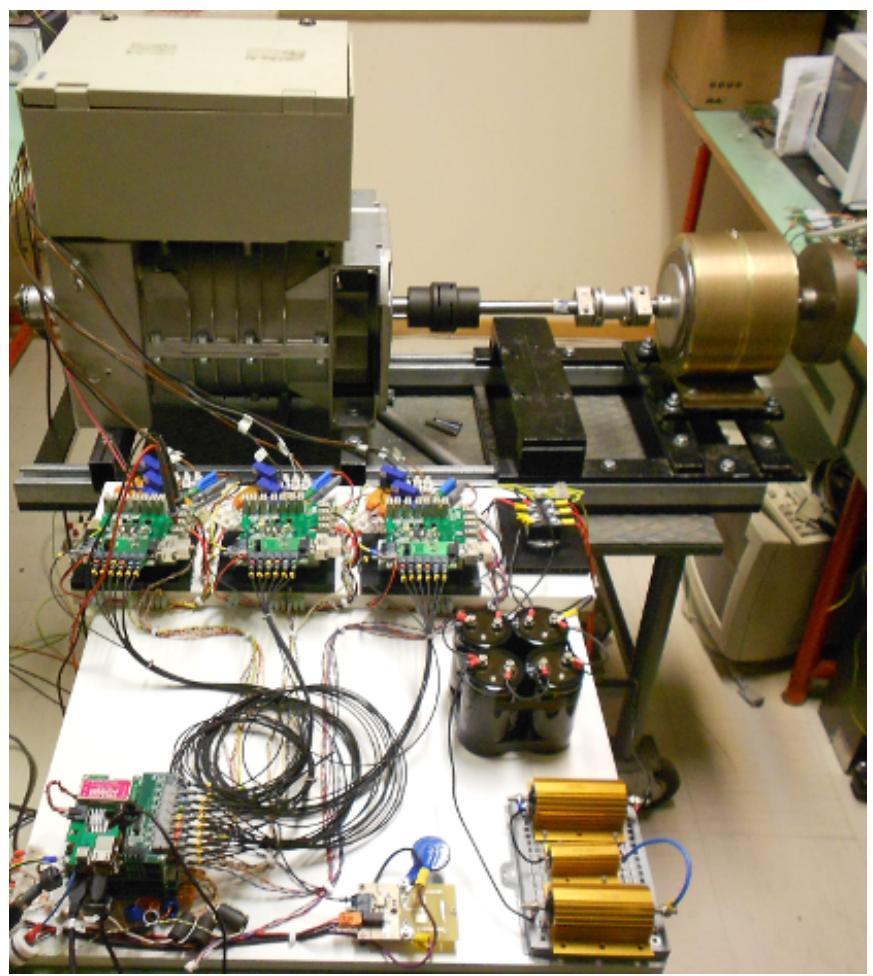

Fig. 7. Multi-three phase trig with motor, brake, $u$ Cube, rectifier, three twolevel converters, nine current sensors, DC-link, bleeding resistors, and brake enable board.

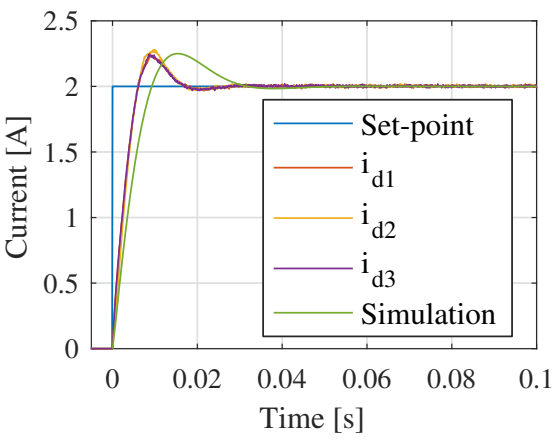

(a) $d$ axis step (2A)

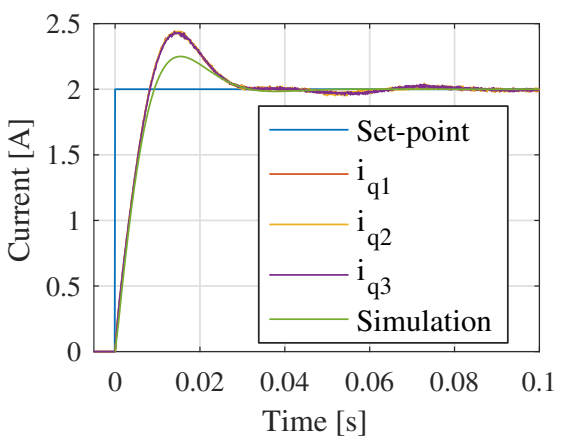

(b) $q$ axis step (2A).

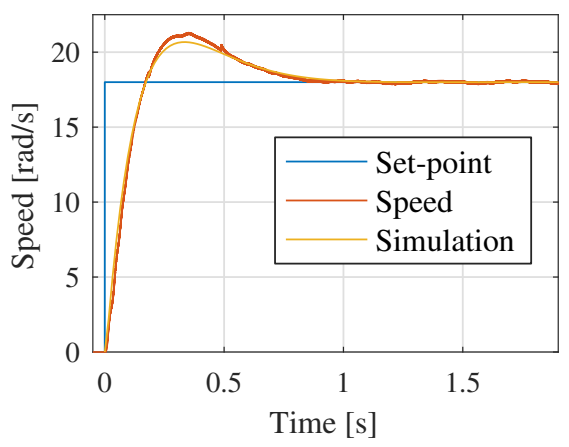

(c) Speed step $(18 \mathrm{rad} / \mathrm{s})$ in CSR.

Fig. 6. $d$-current, $q$-current, and speed loop design validation. 


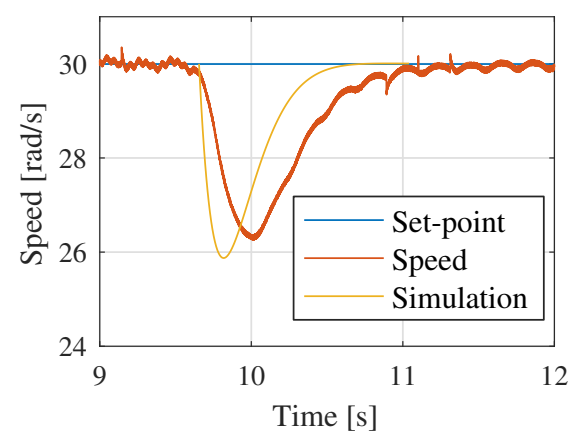

(a) Speed variation with load step in CSR.

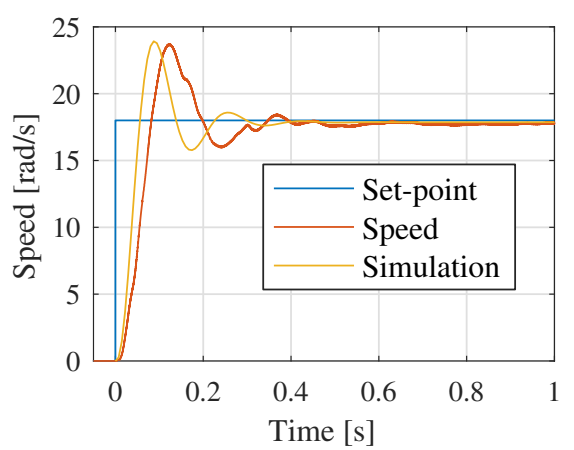

(b) Speed step (18rad/s) without $P I_{D}$.

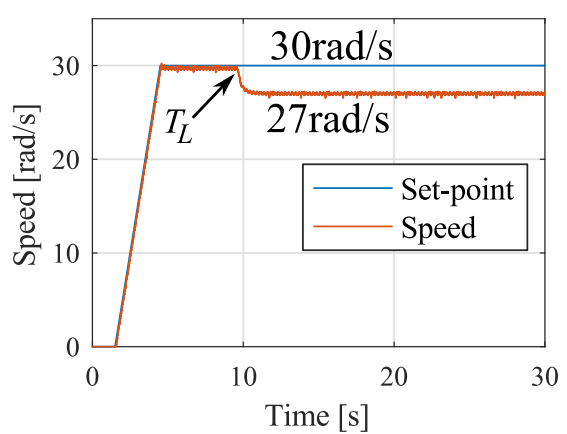

(c) At full load without $P I_{D} \Delta \omega_{\max }=3 \mathrm{rad} / \mathrm{s}$.

Fig. 8. Speed dynamics in Common Speed Reference configuration and speed dynamics as in Fig. 2 but without compensation $P I_{D}$.

cards with fibre optic receivers have been designed. The switching frequency and the sampling period have been set to $10 \mathrm{kHz}$, whilst the DC link voltage was set to $350 \mathrm{~V}$. Current have been measured by nine LEM LA-25P current sensors. In order to produce a load torque, the generator has been coupled to a hysteresis brake enabled by the control platform.

\section{A. Current loop}

Current step responses on $d$ and $q$ axes in locked rotor condition are shown in Fig.s 6a, 6 b.

\section{B. Speed Loop in Common Speed Reference configuration and without compensation loop}

Speed step response and speed variation with load step from zero to full load $T_{L}=55.2 \mathrm{Nm}$ with all the drives in speed mode (CSR) are shown in Fig. 6c, 8a, respectively. Fig. 8b and $8 \mathrm{c}$ show the speed step response and the speed variation with load step without compensation loop. In this particular case the sharing time constant has been set to $30 \mathrm{~ms}$. In Fig. $8 \mathrm{c}$, it is possible to appreciate how the speed drop increases with $T_{L}$.

\section{Compensation loop}

In Fig.s 9a, 9b speed step response and speed variation with load step from zero to full load with system configured like in Fig. 2 are shown.

\section{Power sharing}

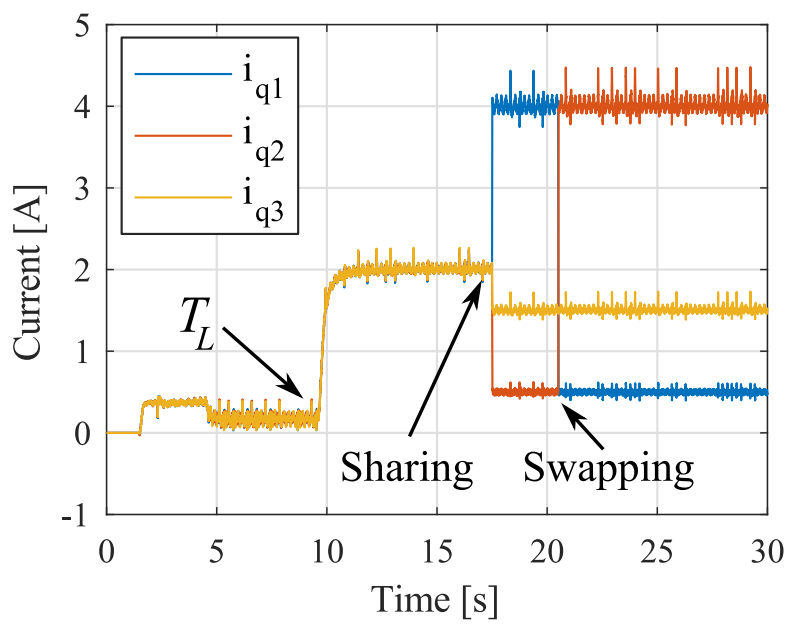

Fig. 10. Power sharing.

Looking at Fig. 10, the $i_{q}$ currents under ramped input from zero to nominal speed are shown. After $10 s$ the brake have been enabled. The system was in (ES) condition until second 17.5. At that point, the droop and the integral coefficients

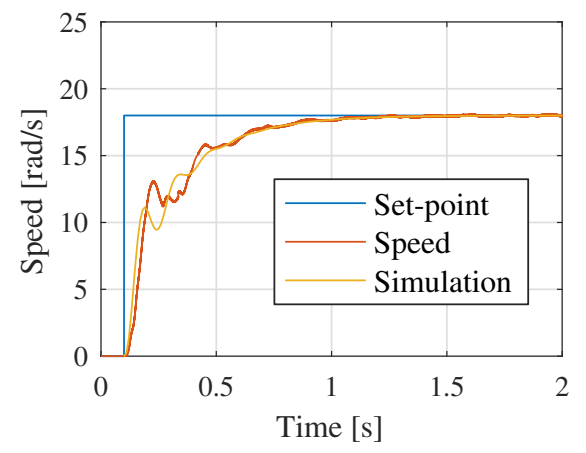

(a) Speed step (18rad/s).

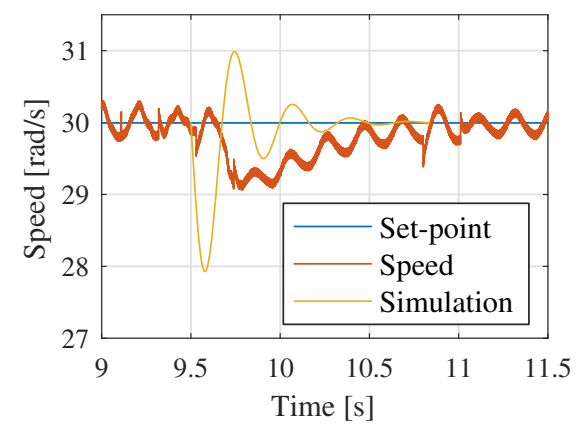

(b) Speed dynamics under load transient.

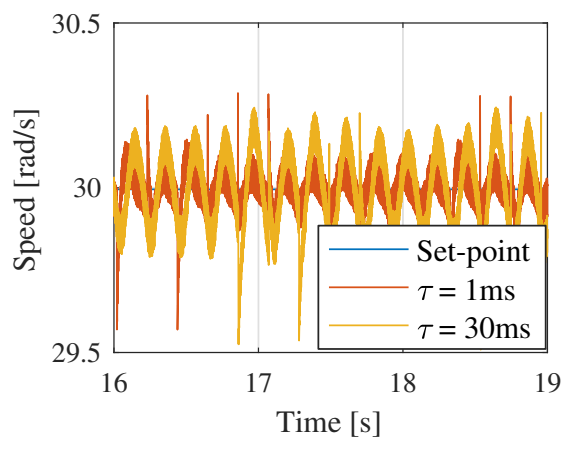

(c) Speed dynamics under sharing transient.

Fig. 9. Speed dynamics with compensation $P I_{D}$ under load and sharing transients for different sharing time constants. 
have been programmed for unbalanced sharing like reported in Table I in the previous Section.

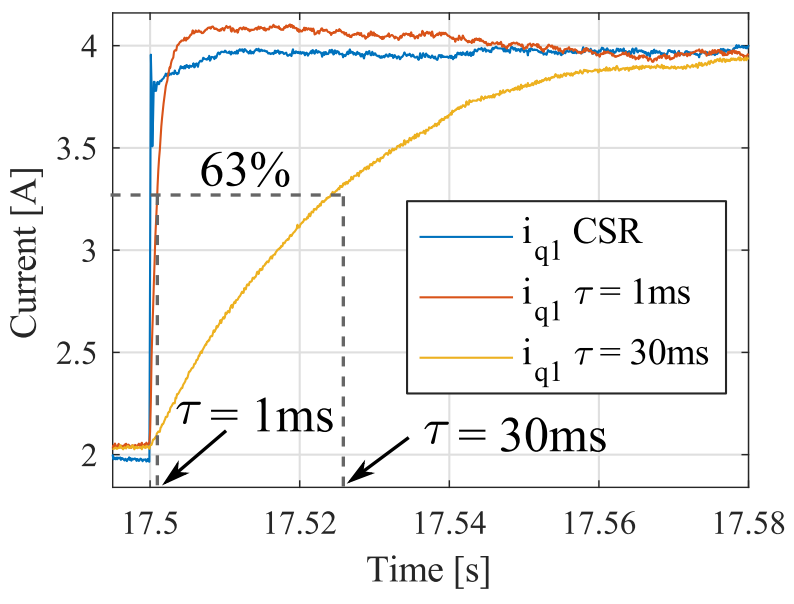

Fig. 11. Sharing time constants comparison.

In Fig. 11, the difference between the current set-point step change - with the system configured in CSR - and the droop controller is highlighted. Whilst current set-point step change leads to current distortion and could potentially excite mechanical resonances, droop controlled transients smoothly reach the steady state with predicted time constants reported in Table I. In Fig. 9c, unaffected speed dynamics under power sharing transient for different time constants is shown.

\section{CONCLUSIONS}

This paper focused on power sharing in multi-three phase speed controlled electrical systems. The so called SpeedDrooped control has been validated on a multi-three phase rig with a salient pole synchronous generator with nine phases. If compared to current steps in Common Speed Reference (CSR) configuration, droop control allows the torque transients to be controlled guaranteeing constant shaft speed. Thanks to the Vector Space Decomposition (VSD), mutual interactions among different sets of windings have been taken into account in the control design. Despite the presence of the electromagnetic couplings within the machine, the droop controller has been successfully validated controlling power sharing transients as predicted.

\section{REFERENCES}

[1] R. Bojoi, S. Rubino, A. Tenconi, and S. Vaschetto, "Multiphase electrical machines and drives: A viable solution for energy generation and transportation electrification," in 2016 International Conference and Exposition on Electrical and Power Engineering (EPE), Oct 2016, pp. 632-639.

[2] E. Levi, "Advances in converter control and innovative exploitation of additional degrees of freedom for multiphase machines," IEEE Transactions on Industrial Electronics, vol. 63, no. 1, pp. 433-448, Jan 2016.

[3] B. Sarlioglu and C. T. Morris, "More electric aircraft: Review, challenges, and opportunities for commercial transport aircraft," IEEE Transactions on Transportation Electrification, vol. 1, no. 1, pp. 54-64, June 2015 .
[4] A. Eid, H. El-Kishky, M. Abdel-Salam, and M. T. El-Mohandes, "On power quality of variable-speed constant-frequency aircraft electric power systems," IEEE Transactions on Power Delivery, vol. 25, no. 1, pp. 55-65, Jan 2010.

[5] M. G. Jahromi, G. Mirzaeva, S. D. Mitchell, and D. Gay, "Powering mobile mining machines: Dc versus ac power,' IEEE Industry Applications Magazine, vol. 22, no. 5, pp. 63-72, Sept 2016.

[6] G. Parise, L. Parise, A. Malerba, F. M. Pepe, A. Honorati, and P. B. Chavdarian, "Comprehensive peak-shaving solutions for port cranes," IEEE Transactions on Industry Applications, vol. PP, no. 99, pp. 1-1, 2016.

[7] Z. Jin, G. Sulligoi, R. Cuzner, L. Meng, J. C. Vasquez, and J. M. Guerrero, "Next-generation shipboard dc power system: Introduction smart grid and dc microgrid technologies into maritime electrical netowrks," IEEE Electrification Magazine, vol. 4, no. 2, pp. 45-57, June 2016.

[8] G. Sulligoi, A. Vicenzutti, and R. Menis, "All-electric ship design: From electrical propulsion to integrated electrical and electronic power systems," IEEE Transactions on Transportation Electrification, vol. 2, no. 4, pp. 507-521, Dec 2016.

[9] G. Pistoia, Electric and Hybrid Vehicles - Power Sources, Models, Sustainability, Infrastructure and the Market. Elsevier, 2010.

[10] J. Wang, Y. Li, and Y. Han, "Integrated modular motor drive design with gan power fets," IEEE Transactions on Industry Applications, vol. 51, no. 4, pp. 3198-3207, July 2015.

[11] R. Abebe, G. Vakil, G. L. Calzo, T. Cox, S. Lambert, M. Johnson, C. Gerada, and B. Mecrow, "Integrated motor drives: state of the art and future trends," IET Electric Power Applications, vol. 10, no. 8, pp. 757-771, 2016.

[12] Y. Zhao and T. Lipo, "Space vector pwm control of dual threephase induction machine using vector space decomposition," Industry Applications, IEEE Transactions on, vol. 31, no. 5, pp. 1100-1109, Sep 1995.

[13] Y. Hu, Z. Q. Zhu, and M. Odavic, "Comparison of two-individual current control and vector space decomposition control for dual three-phase pmsm," IEEE Transactions on Industry Applications, vol. PP, no. 99, pp. 1-1, 2017.

[14] A. Galassini, A. Costabeber, and C. Gerada, "Speed droop control of integrated modular motor drives," in IECON 2015 - 41st Annual Conference of the IEEE Industrial Electronics Society, Nov 2015, pp. $003271-003276$

[15] A. Galassini, A. Costabeber, C. Gerada, G. Buticchi, and D. Barater, "A modular speed-drooped system for high reliability integrated modular motor drives," IEEE Transactions on Industry Applications, vol. 52, no. 4, pp. 3124-3132, July 2016.

[16] A. Tessarolo, L. Branz, and M. Bortolozzi, "Stator inductance matrix diagonalization algorithms for different multi-phase winding schemes of round-rotor electric machines part i. theory," in EUROCON 2015 International Conference on Computer as a Tool (EUROCON), IEEE, Sept 2015, pp. 1-6.

[17] A. Galassini, A. Costabeber, M. Degano, C. Gerada, A. Tessarolo, and S. Castellan, "Distributed current control for multi-three phase synchronous machines in fault conditions," in 2016 XXII International Conference on Electrical Machines (ICEM), Sept 2016, pp. 1036-1042.

[18] A. Galassini, A. Costabeber, and C. Gerada, "Speed control for multithree phase synchronous electrical motors in fault condition," in EUROCON 2017 - International Conference on Smart Technologies (EUROCON), IEEE, Sept 2017.

[19] B. F. W. Allen J. Wood, Power Generation, Operation, and Control. Wiley, 1984.

[20] A. Galassini, G. L. Calzo, A. Formentini, C. Gerada, P. Zanchetta, and A. Costabeber, "ucube: Control platform for power electronics," in 2017 IEEE Workshop on Electrical Machines Design, Control and Diagnosis (WEMDCD), April 2017, pp. 216-221. 